\title{
28 Research Square \\ Impact of the COVID-19 pandemic on the wellbeing of parkrun participants in the United Kingdom
}

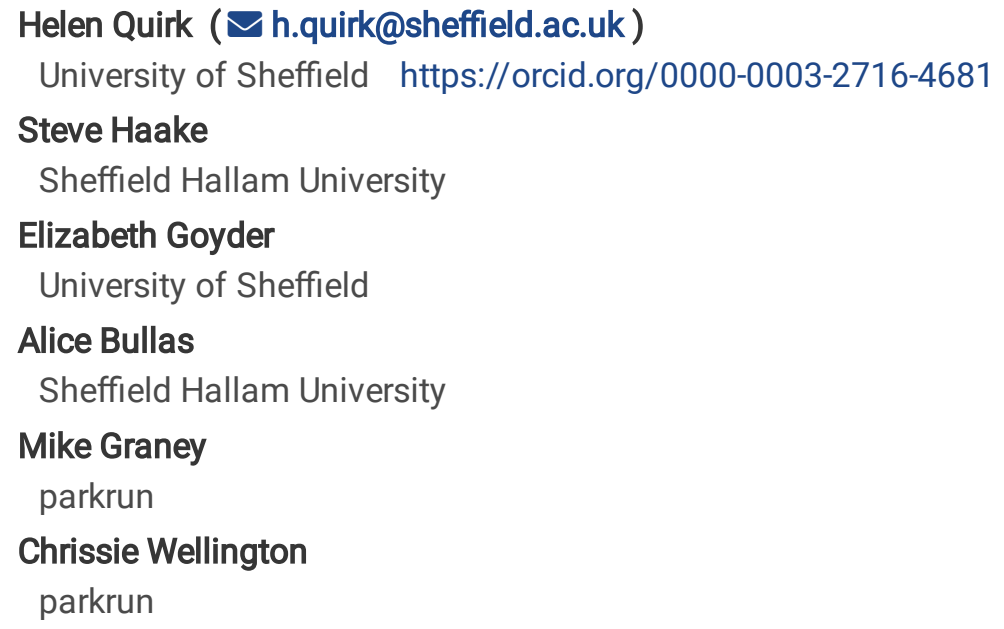

\section{Research Article}

Keywords: COVID-19, mental health, physical activity, longitudinal study, parkrun, community, inequalities

Posted Date: July 7th, 2021

DOI: https://doi.org/10.21203/rs.3.rs-690431/v1

License: (a) (i) This work is licensed under a Creative Commons Attribution 4.0 International License. Read Full License 


\section{Abstract}

\section{Introduction}

Lockdown restrictions imposed across the UK in response to the COVID-19 pandemic had a profound impact on many people's health and wellbeing. People were encouraged to be active, but population surveys suggest some groups found this easier than others. We explored the changes in health, wellbeing and physical activity levels among a sample in the UK who experienced the sudden loss of a weekly community-based physical activity opportunity, parkrun.

\section{Methods}

A sample of UK parkrun participants responded to two surveys; pre-COVID-19 in January/February 2019 and during the COVID19 pandemic in September 2020. Outcomes were happiness, life satisfaction, connections with others, physical health, mental health and physical activity. The sample was stratified by gender, age, deprivation status, physical activity and number of parkruns completed. Demographics were reported using descriptive statistics. Distributions between sub-groups were compared using Chi-square tests while differences in outcomes were determined using the Mann-Whitney $\mathrm{U}$ test. Open text responses were also analysed.

\section{Findings}

Happiness, life satisfaction, connections with others, physical health and mental health of 450 parkrun participants were negatively impacted for all sub-groups, although the impact was not experienced equally. The COVID-19 pandemic negatively impacted the mental wellbeing of a greater proportion of females, younger adults, inactive people, those from higher deprivation areas, and those who had completed fewer parkruns.

\section{Conclusions}

There is evidence that the wellbeing of those who were more active, and those more involved in a community-based physical activity initiative pre-pandemic, was less negatively affected during the COVID-19 lockdown.

\section{Declarations}

\section{Acknowledgements}

The authors would like to thank Allison Dunne for her helpful critique of the final manuscript.

\section{Ethics}

Ethical approval for the original Health and Wellbeing Survey was granted by Sheffield Hallam University Research Ethics Committee on 24/07/2018 (reference number: ER7034346). Ethical approval for this secondary data analysis study was granted by the same ethics committee on 4/12/2020 (reference number ER29077901).

\section{Funding}

The parkrun Health and Wellbeing Survey 2018 was funded by parkrun. CW and MG are members of parkrun staff who contributed to the conduct of the survey and write-up of this manuscript. For the preparation of the manuscript, $\mathrm{HQ}$ is funded by a National Institute for Health Research (NIHR) School for Public Health Research (SPHR) post-doctoral launching fellowship. Other authors have no other personal funding to declare.

The views, thoughts, and opinions expressed in the manuscript belong solely to the author/s, and do not necessarily reflect the position of parkrun, the parkrun Research Board or funders.

\section{Conflicts of interest}


CW and MG are parkrun staff members. SH, AB, EG and HQ are members of the parkrun research board. All authors except EG are parkrun registrants/participants.

\section{Lay Summary}

A sample of 450 UK parkrun participants responded to two surveys; one before the COVID-19 pandemic and one during the pandemic. Outcomes were happiness, life satisfaction, connections with others, physical health, mental health and physical activity. Physical activity fell by $6 \%$ while happiness and life satisfaction fell by $12 \%$. People experienced the worst negative impact on their connections with others. The pandemic was found to affect more women, younger adults, those from more deprived neighbourhoods, those who were least active at parkrun registration and those who had completed a lower number of parkrun events in the 12 months prior to the close of parkrun events. The role that community-based physical activity initiatives will have in bringing people's mental health, connections with others, happiness and life satisfaction back to pre-COVID-19 levels in post-lockdown periods needs further investigation and ongoing monitoring.

\section{Introduction}

In March 2020, a nationwide 'lockdown' in the United Kingdom (UK) in response to coronavirus disease 2019 (COVID-19), placed stringent restrictions on travel, social interaction, and access to public spaces with the aim of slowing the spread of the virus and protecting healthcare services. People were advised to 'stay at home', only leaving for essential reasons. The closure of 'non-essential' businesses, organisations and spaces included leisure and fitness centres, gyms, swimming pools, physical activity events and sports clubs. This had a profound impact on the quality and quantity of social interactions and individual lifestyles (Bu et al., 2020) with detrimental consequences to social isolation and loneliness (Bu et al., 2020), mental distress (Banks and Xu, 2020), happiness and life satisfaction (Krekel et al., 2020), especially among women, younger adults, people from black and minority ethnic backgrounds and those with lower household income (Fancourt et al., 2020a).

Despite the closure of sport, exercise and physical activity facilities, physical activity came into the spotlight as governments across the world encouraged people to become and stay active as an 'essential activity' for their health and wellbeing (Payne, 2020, World Health Organization, 2020). Much interest was given to population level changes in physical activity (Stockwell et al., 2021). Research from the beginning of lockdown in March 2020 suggested that higher proportions of the UK population were self-reporting meeting physical activity guidelines compared to preceding years (Smith et al., 2020a), which was supported by Google Trends data from the UK (Ding et al., 2020). Conversely, Sport England data from across the COVID-19 pandemic suggests that the lockdown restrictions had a negative impact on the type and volume of activity people were doing especially during initial stages of the pandemic (between mid-March and mid-May) (Sport England, 2021). The proportion of the population classed as "active" dropped by $7.1 \%$ (over 3 million fewer active adults) compared to the 12 months before (Sport England, 2021).

Collectively, the available evidence into physical activity changes is difficult to compare, generalise and interpret due to methodological differences, seasonal variation in activity levels and the changing COVID-19 lockdown restrictions over place and time. Though what became clear across all the evidence was that physical activity levels differed depending on sociodemographic characteristics such as age, sex, socioeconomic status, disability status, ethnicity and pre-lockdown physical activity level (Smith et al., 2020a, Stockwell et al., 2021, Sport England, 2021, Faulkner et al., 2021). This warrants investigation due to its potential to contribute and reinforce existing health inequalities (Gidlow et al., 2006, Stringhini et al., 2010).

The COVID-19 pandemic restrictions not only meant changes in the levels and type of physical activity but also a loss of social interaction. Feeling a sense of belonging to a social group is a protective mechanism against social isolation, loneliness and poor mental health (Holmes et al., 2020). The social element of participation is likely to have been lost due to lockdown measures. It is therefore important to explore any changes in health, wellbeing and physical activity levels among those who had their community-based physical activity opportunities abruptly removed during lockdown restrictions. 
We examine this issue in the context of parkrun, a community-based physical activity opportunity that suspended its 2,200+ worldwide events in March 2020 (over 1,000 of which take place in the UK). parkruns are free, weekly, 5 kilometre events where people can participate as a runner, walker or volunteer (www.parkrun.com). In the UK, before events were closed due to the COVID-19 pandemic, around 170,000 people were taking part each week. parkrun has removed many of the barriers to physical activity, encouraging participation by women (Stevinson and Hickson, 2013), older people (Grunseit et al., 2018), people with long-term health conditions (Quirk and Haake, 2019), people who were previously inactive (Quirk et al., 2020) and those living in areas of high deprivation (Smith et al., 2020b). Research suggests that the health and wellbeing gains of participation are derived from the friendly, welcoming and social nature of the events (Grunseit et al., 2020). With the abrupt cancellation of parkrun events in March 2020, the parkrun population provides a unique opportunity to explore change over time in health and wellbeing among relatively active people.

In this study, we sought to understand how the health, wellbeing and physical activity level of UK parkrun participants changed during the COVID-19 pandemic and the extent to which people from different sub-groups differed.

\section{Methods}

Ethical approval for the original Health and Wellbeing Survey was granted by Sheffield Hallam University Research Ethics Committee on 24/07/2018 (reference number: ER7034346). Ethical approval for this secondary data analysis study was granted by the same ethics committee on 4/12/2020 (reference number ER29077901).

\section{Study samples}

This study uses a single sample of parkrun participants responding to surveys at 2 time points, described below.

\section{The Health and Wellbeing Survey (labelled "pre-COVID")}

In 2018, parkrun commissioned the Advanced Wellbeing Research Centre (AWRC) at Sheffield Hallam University (UK) to conduct a study into the health and wellbeing of the UK parkrun community (Haake, Quirk, and Bullas 2018); including participants in England, Scotland, Wales and Northern Ireland. In the longitudinal arm of the study, new parkrun registrants $(50,509)$ were emailed in January/February 2019 with an invite to complete an online survey and were followed up with the same survey 6 months later in July 2019 (receiving 567 responses). This paper only reports the data from January/February 2019 (i.e., "preCOVID").

The Health and Wellbeing Survey measured happiness, life satisfaction, self-reported physical activity level, motives for participation, health status, healthcare usage, mental wellbeing, perceived impact of parkrun and the impact of parkrun on social opportunities. Participants in the Health and Wellbeing Survey gave permission for their anonymised responses to be used for further research.

\section{The parkrun COVID-19 survey (labelled "COVID")}

During the COVID-19 pandemic in September 2020, 20 months after the parkrun Health and Wellbeing survey was distributed, parkrun sent a COVID-19 survey to parkrun participants in the UK; including participants in England, Scotland, Wales and Northern Ireland. The online parkrun COVID-19 survey was sent via email to a stratified random sample balanced for gender, age and number of parkrun walk/runs completed in the 12 months prior to $18^{\text {th }}$ March 2020. This represented 57,941 parkrun participants and included 2,560 respondents from the pre-COVID Health and Wellbeing Survey. The parkrun COVID-19 survey aimed to understand the impact of the COVID-19 pandemic on the health and wellbeing of parkrun participants and their thoughts about returning to parkrun when events were relaunched in the UK. Participants in the parkrun COVID-19 survey gave permission for their responses to be shared with researchers for the purposes of further research.

Combined dataset used in this secondary analysis

Page $4 / 20$ 
Responses to the Health and Wellbeing Survey and the parkrun COVID-19 survey were matched at the person-level using parkrun Athlete ID (provided to all parkrun registrants to identify them on the parkrun database and enable the collation of all their parkrun participation data) and date of birth across the two databases. This resulted in a combined (linked) dataset of 450 respondents who had completed both surveys and thus allowed a comparison of responses over time (before and during the pandemic).

\section{Outcomes}

\section{Demographic variables}

Additional demographic variables not collected in the surveys were extracted from the parkrun database after the matching process:

- Gender (female and male);

- Age derived from date of birth;

- Index of multiple deprivation (IMD) derived from postcode;

- Self-reported physical activity level at parkrun registration;

- Number of parkrun events completed before parkrun events closed in March 2020.

\section{Health and wellbeing}

Mental wellbeing was captured using questions on happiness, life satisfaction, mental health and connections with others. The pre-COVID and COVID surveys both used the Office of National Statistics (ONS) personal wellbeing scales questions for happiness and life satisfaction: i) Overall, how happy did you feel yesterday? and ii) Overall, how satisfied are you with your life nowadays? Respondents were asked to respond on a scale of 0 to 10 , where 0 is "not at all" and 10 is "completely".

In the COVID survey, participants were asked: How has your i) happiness, and ii) satisfaction with life iii) connections with others in your community, iv) physical health, and v) mental health been impacted by the COVID-19 pandemic? On a 5-point Likert scale, respondents were given the options: major positive impact, moderate positive impact, no impact, moderate negative impact, major negative impact.

\section{Self-reported physical activity level}

The pre-COVID and COVID surveys both used the Milton, Bull \& Bauman (2011) single item physical activity question which asked: In the past week, on how many days have you done a total of 30 minutes or more of physical activity, which was enough to raise your breathing rate? This may include sport, exercise, and brisk walking or cycling for recreation or to get to and from places, but should not include housework or physical activity that may be part of your job. Respondents could answer: 0 days, 1 day, 2 days etc up to 7 days.

\section{Open text responses}

The COVID survey gave respondents the option of providing an open-text response to the question: "Is there anything you want to add about the impact of the pandemic, and the absence of parkrun events on your health and wellbeing?"

\section{Data analysis}

Data was visually checked in Microsoft Excel by one researcher (SH) and analysed using frequency counts, means, standard deviations, medians, minimum and maximum and inter-quartile range. For categorical data: $\mathrm{N}$ and \%.

\section{Stratification}

The sample was stratified by the following: 
- Gender: female and male (Supplementary Material 1a);

- Socioeconomic status (SES): using the indices of multiple deprivation (IMD), classified into four quartiles (Q1, Q2, Q3, Q4) and segregated into 'Low IMD' (those in the most deprived areas; IMD Q1 and Q2) and 'High IMD' (those in the least deprived areas; IMD Q3 and Q4) (Supplementary Material 1c);

- Age: derived from the date of birth and segregated into 'younger adults' (less than 55 years of age; mean age 41.2) and 'older adults' (55 years or over; mean age 62.4) (Supplementary Material 1b);

- Activity level: derived from a physical activity question asked at parkrun registration and segregated into 'lower activity' (those reporting 0,1 or 2 days per week of at least 30 minutes moderate exercise) and 'higher activity' (those reporting 3 and 4 or more days per week of at least 30 minutes moderate exercise) (Supplementary Material 1d);

- parkrun engagement level: derived from parkrun participation records and segregated either side of the median into 'low parkruns' ( $\leq 9$ parkruns completed in the previous 12 months; mean number of parkruns 3.7) and 'high parkruns' (>9 parkruns completed in the previous 12 months; mean number of parkruns 23.2) (Supplementary Material 1e).

The change in physical activity between the pre-COVID and COVID surveys was determined using the single item activity question with a maximum change of \pm 7 days of activity per week.

Distributions between sub-groups were compared using Chi-square tests with the significance of specific categories analysed using partitioned Chi-square tests; these were calculated in Excel for Mac (v16.43). Happiness, life satisfaction and single item physical activity level were non-parametric (i.e. had medium to large values of $Z_{\text {skew }}$ and $Z_{\text {kurt }}$ ) and differences were determined using the Mann-Whitney U test in SPSS (v26). Effect sizes were calculated using Cohen's $d$ using pooled standard deviation.

The open-ended survey responses were analysed in Excel using content analysis and inductive coding (O'Cathain and Thomas, 2004). One researcher (HQ), an experienced qualitative researcher, devised a coding frame inductively from the data and manually assigned codes to the verbatim responses that captured what the respondent was saying (i.e., the thematic content of the response). Content analysis stopped when the researcher had reached a point of having summarised all the responses into themes. Themes were presented as numbers and proportions. Verbatim comments were extracted to illustrate the themes.

\section{Findings}

\section{Sample characteristics}

Table 1 shows the demographics of the full sample; the demographics of all sub-groups are given in Supplementary Material 1. The mean age of the sample was 47.6 years with a slight skew towards younger respondents. The age range was 16 to 80 years and $55.3 \%$ were female. The proportion of the sample increased linearly with IMD quartile from $11.2 \%$ for quartile 1 (most deprived) to $35.1 \%$ for quartile 4 (least deprived). $7.4 \%$ were inactive at parkrun registration (i.e. reported doing less than one day of least 30 minutes of moderate exercise per week) with the mode at three days of activity per week (31.7\% of the cohort).

\section{[insert Table 1]}

In the year prior to parkrun closing due to the COVID-19 pandemic (13 to 14 months after the pre-COVID survey), participants had done a mean of 13.3 parkruns, i.e. just over one per month; the distribution was highly skewed, with a median of 9 parkruns and an inter-quartile range of 3 to 21 parkruns.

\section{Happiness, life satisfaction and physical activity}

\section{Full cohort}

Table 2a-2c shows happiness, life satisfaction and physical activity at the pre-COVID and at COVID surveys for the full cohort (all) and the sub-groups. Happiness fell from 7.48 before the COVID-19 pandemic to 6.60 during the COVID-19 pandemic by a mean of -0.88 ; similarly, life satisfaction fell from 7.48 to 6.56 by a mean of -0.92 . Values of happiness and life satisfaction during the COVID-19 pandemic were significantly lower for all sub-groups compared to before the COVID-19 pandemic (Tables 
$2 a$ and $2 b ; p<0.01$ or $p<0.001$ with moderate to large effect sizes). The physical activity level for the full cohort fell from 3.47 to 3.22 days per week by 0.21 days per week (Table $2 c ; p<0.05$ with a small effect size).

The following sections describe the statistically significant findings for each sub-group (Tables 2a to 2c).

[insert Table 2a-2c]

Females vs males

Females had higher happiness and life satisfaction before the COVID-19 pandemic than during the COVID-19 pandemic. Although the differences between genders were not significantly different between time points, the change in life satisfaction from before to during the COVID-19 pandemic was, i.e. for females it dropped by 1.17 while for men it dropped by 0.62 (Table $2 b$; effect size $=0.26, p<0.01$ ). There was no statistically significant difference in physical activity levels between females and males.

\section{Younger vs older}

Happiness and life satisfaction were statistically higher for the older sub-group compared to the younger sub-group both before the COVID-19 pandemic and during the COVID-19 pandemic (Tables $2 a$ and $2 b ; p<0.01$ ). There was no significant difference in physical activity levels between the two sub-groups at either time point (Table 2c).

Low IMD (most deprived) vs high IMD (least deprived)

Happiness and life satisfaction appeared to be lower at both time points for the low IMD group compared to the high IMD group, although this was only significant for happiness during the COVID-19 pandemic (Table 2a; 6.30 vs 7.45, effect size $=0.23$, $p<0.05)$. There was no significant difference for physical activity levels between the two sub-groups at either time point, although the change in physical activity level from before to during the COVID-19 pandemic was significantly larger for the low IMD group compared to the high IMD group, i.e. the activity level of the low IMD group fell by 0.52 days per week while the high IMD group fell by 0.14 days per week (Table 2 c; effect size $0.19, \mathrm{p}<0.05$ ).

\section{Low vs high activity at registration}

Happiness, life satisfaction and physical activity were lower for the low activity group compared to the high activity group before and during the COVID-19 pandemic. The change in activity from before to during the COVID-19 pandemic was greater for the high activity sub-group compared to the low activity group (Table $2 c ;-0.57$ vs 0.10 , effect size $0.34, p<0.05$ ).

\section{Low vs high number of parkruns}

Happiness and life satisfaction tended to be higher before the COVID-19 pandemic for the low parkruns sub-group compared to the high parkruns sub-group; conversely these variables were lower for the low parkruns sub-group during the COVID-19 pandemic (Tables $2 a$ and $2 b$ ). Although the differences between sub-groups were not significant, the change in happiness was significantly greater for the low parkruns sub-group with a drop of -1.10 compared to -0.70 (Table 2a; effect size 0.19 , p<0.05).

\section{Perceived impact of the COVID-19 pandemic}

Tables 3a to 3e show the perceived impact of the COVID-19 pandemic. The most reported negative impact was on connections with others (73\%), while physical health had the lowest negative impact (41\%) and the largest positive impact (26\%). Around a third of respondents reported no impact of the COVID-19 pandemic on either their physical or mental health. The following sections describe the statistically significant findings for each sub-group.

[insert Table 3a-3e]

Females vs males 
There was little statistical difference between females and males although there were indications that a larger proportion of females improved their connections with others during the COVID-19 pandemic (Table 3c; $17 \%$ vs $9 \%$, $p<0.05$ ) and a larger proportion of females reported worse physical health (Table $3 d ; 46 \%$ vs $34 \%, p<0.05$ ).

\section{Younger vs older adults}

A larger proportion of younger adults reported a major negative impact of the COVID-19 pandemic on their happiness when compared to older adults (Table 3a; $10 \%$ vs $1 \%, \mathrm{p}<0.01$ ). Similar differences between younger and older adults reporting a major negative impact were found for life satisfaction (Table $3 b ; 8 \%$ vs $2 \%, p<0.05$ ) and mental health (Table $3 e ; 10 \%$ vs $1 \%, p<0.01$ ). Overall, $66 \%$ of younger adults reported worse mental health compared to $42 \%$ of older adults (Table $3 e ; p<0.001$ ). Conversely, a larger proportion of older adults than younger adults reported a moderately positive impact of the COVID-19 pandemic on their connections with others (Table $3 c ; 16 \%$ vs $10 \%, p<0.05$ ).

A large proportion of older adults reported no impact to their physical health than younger adults (Table $3 \mathrm{~d} ; 39 \%$ vs $30 \%$, $p<0.01$ ); this was also true for mental health (Table $3 e ; 52 \%$ vs $28 \%, p<0.001$ ).

\section{Low IMD (most deprived) vs high IMD (least deprived)}

A larger proportion of those from the low IMD sub-group reported a major negative impact of the COVID-19 pandemic on their happiness when compared to the high IMD sub-group (Table 3a; $12 \%$ vs $4 \%, \mathrm{p}<0.05$ ). Overall, $50 \%$ of the low IMD sub-group reported worse physical health compared to $37 \%$ of the high IMD sub-group (Table $3 d ; p<0.01$ ). Similarly, $66 \%$ of the low IMD sub-group reported worse mental health compared to $56 \%$ of the high IMD sub-group (Table 3e; $\mathrm{p}<0.05$ ). Conversely, a larger proportion of the high IMD sub-group reported a moderate positive impact of the pandemic on their connections with others compared to the low IMD sub-group (Table $3 \mathrm{c} ; 14 \%$ vs $8 \%$; $p<0.05$ ).

A larger proportion of those from the high IMD sub-group reported no impact to their life satisfaction than those from the low IMD sub-group (Table $3 \mathrm{~b} ; 22 \%$ vs $14 \%$, $\mathrm{p}<0.01$ ); this was also true for physical health (Table $3 \mathrm{~d} ; 35 \% \mathrm{vs} 26 \%$, $\mathrm{p}<0.05$ ) and mental health (Table $3 e ; 38 \%$ vs $28 \%$, p $<0.05$ ).

Low vs high activity

A larger proportion of those who had low activity levels at registration reported a moderately negative impact of the COVID-19 pandemic on their life satisfaction when compared to those who reported higher levels of activity (Table $3 \mathrm{~b} ; 68 \%$ vs $56 \%$, $\mathrm{p}<0.05$ ), and also their physical health (Table $3 \mathrm{~d} ; 45 \%$ vs $32 \%, p<0.01$ ). A slightly larger proportion of those from the high activity sub-group reported no impact of the COVID-19 pandemic to their life satisfaction than those from the low activity sub-group (Table 3c; $16 \%$ vs $10 \%$, p<0.05).

Low vs high number of parkruns

A larger proportion of those who did a low number of parkruns reported a moderately negative impact of the COVID-19 pandemic on their happiness when compared to those who did a high number of parkruns (Table $3 a ; 68 \%$ vs $56 \%, p<0.01$ ).

\section{Open-text responses}

125 respondents ( $28 \%$ of the COVID survey sample) provided an open-text response. $80 \%$ of those providing an open text response (100 respondents) described aspects of parkrun that they missed. Data coding led to the generation of 11 themes that captured how people had responded to the absence of parkrun, to the COVID-19 pandemic and other comments about parkrun in relation to its anticipated return (see Supplementary Material 2 for all themes with illustrative quotes). The top 2 themes, with illustrative quotes are outlined in Table 4.

[insert Table 4]

\section{Discussion}


We have been able to analyse changes in health, wellbeing and physical activity among a sample of parkrun participants who had completed surveys before and during the COVID-19 pandemic. Happiness and life satisfaction dropped by about $12 \%$ in the 20-month period between parkrun registration (pre-COVID) and during the COVID-19 pandemic. The happiness and life satisfaction scores fell by almost 1 point below the pre-COVID-19 national averages for England and Wales 2019-2020 (Office of National Statistics (ONS), 2018) though were higher than those reported in other England studies during the COVID-19 pandemic (Carson et al., 2020).

Whilst the happiness and life satisfaction among all sub-groups were impacted negatively, this was not experienced similarly across groups. Happiness levels fell more among younger, female and those from more deprived areas. Life satisfaction levels fell more among females, more deprived and lower activity level respondents. These findings are consistent with the reports of younger adults and females in the UK demonstrating worse mental health symptoms and larger deteriorations in mental health compared to older adults and males during the COVID-19 pandemic (Fancourt et al., 2020b, Pierce et al., 2020, Krekel et al., 2020). The gender differences are consistent with pre-existing health inequalities (Pierce et al., 2020) and have been attributed in part to informal caring responsibilities and childcare responsibilities held alongside working commitments by females during the COVID-19 pandemic (Mak et al., 2021).

Just over half of our sample reported a negative impact of the pandemic on mental health with $6 \%$ reporting a positive impact of the pandemic on mental health. Again, younger adults were more likely to report a negative impact of the pandemic on their mental health than older adults, which supports other findings (O'Connor et al., 2020, Office of National Statistics (ONS), 2020, Pierce et al., 2020). We did not find any differences in the mental wellbeing impact of the pandemic on people from more deprived neighbourhoods compared to those in less deprived neighbourhoods which could be attributed to higher physical activity levels (Johansson et al., 2019), though this needs investigating further.

Our data show that the greatest negative impact of the COVID-19 pandemic among our sample was on people's connections with others. Younger adults were more detrimentally impacted. Our open-text responses captured how people missed the socialisation and community parkrun provides, perhaps more so than the physical activity itself. This is supported by previous parkrun research that has highlighted that the community and social connections are both major appeal and positive outcome of parkrun participation (Grunseit et al., 2020). Our findings suggest that given many respondents were able to maintain their level of physical activity during the COVID-19 lockdown, physical activity on its own was not enough to support mental wellbeing, showing that the lack of social connections had the most detrimental impact. The importance of maintaining social connections during the COVID-19 pandemic has been strongly advocated as a potential buffer against negative physical and mental health outcomes (Nitschke et al., 2020). This suggests that a return to parkrun may mitigate some of the negative mental health effects of lockdown. Further research is needed to find out if this is the case.

Less than half of respondents reported a negative impact of the pandemic on their physical health and around a quarter reported a positive impact on the pandemic on their physical health. This may be attributed to physical activity levels and our sample's ability to roughly maintain their activity level during the pandemic (still around 3 days a week of activity). Physical activity levels fell across the whole sample by about $6 \%$, though there was evidence that some people increased their activity level whilst others decreased, which is consistent with the existing, but somewhat mixed evidence base (Bann et al., 2020). The open-text comments suggest that people's physical activity response to the pandemic may have been influenced by motivation (i.e., having an incentive to be active alone) and opportunity (i.e., time in relation to other commitments), which varied according to living, working and caring arrangements. parkrun provided some people with motivation and incentive to be active and whereas others lacked sufficient incentive to remain active in the absence of parkrun events.

Participating in events like parkrun, when they return, could contribute to the enhancement of mental wellbeing, especially among younger female participants during future lockdowns, in the 'back to normal' transition and 'post-lockdown' periods (Sallis et al., 2020). Further research is needed to find out if this is the case.

\section{Methodological considerations}


Findings should be interpreted in the context of the following methodological considerations. Firstly, the self-reported measures may have been biased by measurement errors and reporting biases. Secondly, the surveys were conducted at different times of the year (January/February and September) so the findings should be interpreted with consideration of potential seasonality effects. Thirdly, it is possible that those who provided a response could be different from other parkrun participants, and therefore caution must be taken when extrapolating these findings to a wider population. Fourthly, in our exploration of potential inequalities, it is important to note the following limitations. The socioeconomic status of respondents was not inferred from employment, income etc. but was inferred from IMD which was sourced by the postcode provided at parkrun registration. This gives an average for the area lived in when the respondent first registered with parkrun, it does not guarantee that it is specific to the person. A further limitation of our analysis is that we did not consider the impact of the COVID-19 pandemic on ethnic minority groups which have shown inequalities in physical activity levels during the COVID-19 pandemic (Bann et al., 2020). Finally, our analysis was unable to distinguish the impact of the pandemic from the impact of the lockdown policy on health and wellbeing (Foa et al., 2020).

\section{Conclusions}

The overall wellbeing of a cohort of 450 parkrun participants declined during the COVID-19 pandemic. Physical activity fell by $6 \%$ while happiness and life satisfaction fell by $12 \%$. The parkrun participants perceived that the most notable detrimental impact of the pandemic was on their connections with others. The pandemic was found to affect more women, younger adults, those from more deprived neighbourhoods, those who were least active at registration and those who had completed a lower number of parkrun events in the 12 months prior to the close of parkrun events. The role that community-based physical activity initiatives will have in bringing people's mental health, connections with others, happiness and life satisfaction back to preCOVID-19 levels in post-lockdown periods needs further investigation and ongoing monitoring.

\section{References}

BANKS, J. \& XU, X. 2020. The mental health effects of the first two months of lockdown and social distancing during the Covid19 pandemic in the UK. IFS Working Papers.

BANN, D., VILLADSEN, A., MADDOCK, J., HUGHES, A., PLOUBIDIS, G., SILVERWOOD, R. \& PATALAY, P. 2020. Changes in the behavioural determinants of health during the coronavirus (COVID-19) pandemic: gender, socioeconomic and ethnic inequalities in 5 British cohort studies. medRxiv.

BU, F., STEPTOE, A. \& FANCOURT, D. 2020. Who is lonely in lockdown? Cross-cohort analyses of predictors of loneliness before and during the COVID-19 pandemic. Public Health, 186, 31-34.

CARSON, J., PRESCOTT, J., ALLEN, R. \& MCHUGH, S. 2020. Winter is coming: age and early psychological concomitants of the Covid-19 pandemic in England. Journal of Public Mental Health.

DING, D., DEL POZO CRUZ, B., GREEN, M. A. \& BAUMAN, A. E. 2020. Is the COVID-19 lockdown nudging people to be more active: a big data analysis. BMJ Publishing Group Ltd and British Association of Sport and Exercise Medicine.

FANCOURT, D., BU, F., MAK, H. W. \& STEPTOE, A. 2020a. Covid-19 Social Study Results Release 27 [Online]. Available: http://allcatsrgrey.org.uk/wp/download/public_health/mental_health/3d9db5_56829e7218df4524b304636d226a6198.pdf [Accessed 11/02/2021].

FANCOURT, D., STEPTOE, A. \& BU, F. 2020b. Trajectories of anxiety and depressive symptoms during enforced isolation due to COVID-19: longitudinal analyses of 36,520 adults in England. medRxiv.

FAULKNER, J., O’BRIEN, W. J., MCGRANE, B., WADSWORTH, D., BATTEN, J., ASKEW, C. D., BADENHORST, C., BYRD, E., COULTER, M. \& DRAPER, N. 2021. Physical activity, mental health and well-being of adults during initial COVID-19 containment strategies: A multi-country cross-sectional analysis. Journal of science and medicine in sport, 24, 320-326. 
FOA, R., GILBERT, S. \& FABIAN, M. O. 2020. COVID-19 and subjective well-being: Separating the effects of lockdowns from the pandemic. Available at SSRN 3674080.

GIDLOW, C., JOHNSTON, L. H., CRONE, D., ELLIS, N. \& JAMES, D. 2006. A systematic review of the relationship between socioeconomic position and physical activity. Health Education Journal, 65, 338-367.

GRUNSEIT, A., RICHARDS, J. \& MEROM, D. 2018. Running on a high: parkrun and personal well-being. BMC public health, 18, 59.

GRUNSEIT, A. C., RICHARDS, J., REECE, L., BAUMAN, A. \& MEROM, D. 2020. Evidence on the reach and impact of the social physical activity phenomenon parkrun: A scoping review. Preventive Medicine Reports, 101231.

HOLMES, E. A., O'CONNOR, R. C., PERRY, V. H., TRACEY, I., WESSELY, S., ARSENEAULT, L., BALLARD, C., CHRISTENSEN, H., SILVER, R. C. \& EVERALL, I. 2020. Multidisciplinary research priorities for the COVID-19 pandemic: a call for action for mental health science. The Lancet Psychiatry.

JOHANSSON, L. M., LINGFORS, H., GOLSÄTER, M., KRISTENSON, M. \& FRANSSON, E. I. 2019. Can physical activity compensate for low socioeconomic status with regard to poor self-rated health and low quality-of-life? Health and quality of life outcomes, $17,33$.

KREKEL, C., SWANKE, S., DE NEVE, J. E. \& FANCOURT, D. 2020. Are happier people more compliant? Global evidence from three large-scale surveys during Covid-19 lockdowns.

MAK, H. W., BU, F. \& FANCOURT, D. 2021. Mental health and wellbeing amongst people with informal caring responsibilities across different time points during the COVID-19 pandemic: A population-based propensity score matching analysis. medRxiv.

MILTON, K., BULL, F. \& BAUMAN, A. 2011. Reliability and validity testing of a single-item physical activity measure. British journal of sports medicine, 45, 203-208.

NITSCHKE, J. P., FORBES, P. A., ALI, N., CUTLER, J., APPS, M. A., LOCKWOOD, P. L. \& LAMM, C. 2020. Resilience during uncertainty? Greater social connectedness during COVID-19 lockdown is associated with reduced distress and fatigue. British Journal of Health Psychology.

O'CATHAIN, A. \& THOMAS, K. J. 2004. "Any other comments?" Open questions on questionnaires-a bane or a bonus to research? BMC medical research methodology, 4, 1-7.

O'CONNOR, R. C., WETHERALL, K., CLEARE, S., MCCLELLAND, H., MELSON, A. J., NIEDZWIEDZ, C. L., O'CARROLL, R. E., O'CONNOR, D. B., PLATT, S. \& SCOWCROFT, E. 2020. Mental health and well-being during the COVID-19 pandemic: longitudinal analyses of adults in the UK COVID-19 Mental Health \& Wellbeing study. The British Journal of Psychiatry, 1-8.

OFFICE OF NATIONAL STATISTICS (ONS). 2018. Personal well-being in the UK: July 2017 to June 2018 [Online]. Available: https://www.ons.gov.uk/peoplepopulationandcommunity/wellbeing/bulletins/measuringnationalwellbeing/july2017tojune2018 [Accessed 23 Mar 2019].

OFFICE OF NATIONAL STATISTICS (ONS) 2020. Coronavirus and Depression in Adults.

PAYNE, R. 2020. Will the COVID-19 outbreak propel the demand for active spaces or scare the public away? Cities \& Health, 1-4.

PIERCE, M., HOPE, H., FORD, T., HATCH, S., HOTOPF, M., JOHN, A., KONTOPANTELIS, E., WEBB, R., WESSELY, S. \& MCMANUS, S. 2020. Mental health before and during the COVID-19 pandemic: a longitudinal probability sample survey of the UK population. The Lancet Psychiatry, 7, 883-892.

QUIRK, H., BULLAS, A., HAAKE, S., GOYDER, E., GRANEY, M., WELLINGTON, C., COPELAND, R., REECE, L. \& STEVINSON, C. 2020. Exploring the Benefits of Participation in Community-Based Running and Walking Events: A Cross-Sectional Survey of Parkrun Participants. 
QUIRK, H. \& HAAKE, S. 2019. How can we get more people with long-term health conditions involved in parkrun? A qualitative study evaluating parkrun's PROVE project. BMC Sports Science, Medicine and Rehabilitation, 11, 22.

SALLIS, J. F., ADLAKHA, D., OYEYEMI, A. \& SALVO, D. 2020. An international physical activity and public health research agenda to inform COVID-19 policies and practices. Journal of Sport and Health Science.

SMITH, L., JACOB, L., BUTLER, L., SCHUCH, F., BARNETT, Y., GRABOVAC, I., VERONESE, N., CAPERCHIONE, C., LOPEZ-SANCHEZ, G. F. \& MEYER, J. 2020a. Prevalence and correlates of physical activity in a sample of UK adults observing social distancing during the COVID-19 pandemic. BMJ Open Sport \& Exercise Medicine, 6, e000850.

SMITH, R., SCHNEIDER, P., BULLAS, A., HAAKE, S., QUIRK, H., COSULICH, R. \& GOYDER, E. 2020b. Does ethnic density influence community participation in mass participation physical activity events? The case of parkrun in England. Wellcome Open Res, 5 , 9.

SPORT ENGLAND. 2021. The impact of coronavirus on activity levels revealed [Online]. Available:

https://www.sportengland.org/news/impact-coronavirus-activity-levels-revealed [Accessed 20/05/2021].

STEVINSON, C. \& HICKSON, M. 2013. Exploring the public health potential of a mass community participation event. Journal of public health, 36, 268-274.

STOCKWELL, S., TROTT, M., TULLY, M. A., SHIN, J. I., BARNETT, Y. A., BUTLER, L. T., MCDERMOTT, D. T., SCHUCH, F. B. \& SMITH, L. 2021. Changes in physical activity and sedentary behaviours from before to during the COVID-19 pandemic lockdown: A Systematic Review. BMJ Open Sport \& Exercise Medicine.

STRINGHINI, S., SABIA, S., SHIPLEY, M., BRUNNER, E., NABI, H., KIVIMAKI, M. \& SINGH-MANOUX, A. 2010. Association of socioeconomic position with health behaviors and mortality. Jama, 303, 1159-1166.

WORLD HEALTH ORGANIZATION. 2020. Stay physically active during self-quarantine [Online]. Available: https://www.euro.who.int/en/health-topics/health-emergencies/coronavirus-covid-19/publications-and-technicalguidance/noncommunicable-diseases/stay-physically-active-during-self-quarantine [Accessed 15/01/2020].

\section{Tables}

Table 1. Demographics (at registration) of newly registered parkrunners in pre-COVID and COVID surveys.

\begin{tabular}{|c|c|c|c|c|c|c|c|c|c|}
\hline & & $\mathrm{N}$ & Mean & St Dev & Min & Median & IQR & Max & Female \\
\hline Age (years) & & 438 & 47.6 & 13.1 & 16.8 & 48.4 & 39.3-56.8 & 80.8 & $55.3 \%$ \\
\hline Index of multiple deprivation & & $\mathrm{N}$ & Q1 & Q2 & Q3 & Q4 & & & \\
\hline Frequency & All & 436 & 49 & 100 & 134 & 153 & & & \\
\hline Proportion & All & & $11.2 \%$ & $22.9 \%$ & $30.7 \%$ & $35.1 \%$ & & & \\
\hline Activity level at registration & & $\mathrm{N}$ & $<1$ & $\approx 1$ & $\approx 2$ & $\approx 3$ & $\geq 4$ & & \\
\hline Frequency & All & 445 & 33 & 51 & 119 & 141 & 101 & & \\
\hline Proportion & All & & $7.4 \%$ & $11.5 \%$ & $26.7 \%$ & $31.7 \%$ & $22.7 \%$ & & \\
\hline & & $\mathrm{N}$ & Mean & St Dev & Min & Median & IQR & Max & \\
\hline Number of parkruns & All & 356 & 13.3 & 12.3 & 1 & 9 & $3-21$ & 49 & \\
\hline
\end{tabular}

Table 2. Questions on happiness, life satisfaction and physical activity pre-COVID and during the COVID-19 pandemic. Young/old defined as $<55$ and $\geq 55$ years; Low/high IMD $<50 \%$ and $\geq 50 \%$; Low/high activity $\leq$ 'About 2 days per week' and $\geq$ 'About three days per week'; fewer/more parkruns $\leq 9$ runs and $>9$ runs.

(a) Overall, how happy did you feel yesterday? (0-10) 


\begin{tabular}{|c|c|c|c|c|c|c|c|c|c|c|c|c|}
\hline & Happiness & All & Female & Male & Younger & Older & $\begin{array}{l}\text { Low } \\
\text { IMD }\end{array}$ & $\begin{array}{l}\text { High } \\
\text { IMD }\end{array}$ & $\begin{array}{c}\text { Low } \\
\text { activity }\end{array}$ & $\begin{array}{c}\text { High } \\
\text { activity }\end{array}$ & $\begin{array}{c}\text { Low } \\
\text { parkruns }\end{array}$ & $\begin{array}{c}\text { High } \\
\text { parkruns }\end{array}$ \\
\hline & $\mathrm{n}$ & 398 & 216 & 182 & 276 & 122 & 132 & 253 & 178 & 215 & 157 & 155 \\
\hline \multirow{3}{*}{$\begin{array}{l}\text { Pre- } \\
\text { COVID } \\
\text { survey }\end{array}$} & Mean & 7.48 & 7.56 & 7.38 & 7.26 & 7.98 & 7.45 & 7.49 & 7.25 & 7.68 & 7.61 & 7.46 \\
\hline & $\begin{array}{l}\text { Standard } \\
\text { deviation }\end{array}$ & 1.52 & 1.46 & 1.59 & 1.52 & 1.41 & 1.42 & 1.58 & 1.63 & 1.40 & 1.55 & 1.57 \\
\hline & $\begin{array}{r}\text { Effect size } \\
\text { between sub- } \\
\text { groups }\end{array}$ & & & 0.12 & & $* * * 0.48$ & & 0.03 & & $* 0.29$ & & 0.10 \\
\hline \multirow{3}{*}{$\begin{array}{l}\text { COVID } \\
\text { survey }\end{array}$} & Mean & 6.60 & 6.57 & 6.62 & 6.29 & 7.28 & 6.30 & 6.79 & 6.37 & 6.79 & 6.52 & 6.75 \\
\hline & $\begin{array}{l}\text { Standard } \\
\text { deviation }\end{array}$ & 2.20 & 2.26 & 2.12 & 2.28 & 1.82 & 2.32 & 2.08 & 2.31 & 2.09 & 2.15 & 2.09 \\
\hline & $\begin{array}{r}\text { Effect size } \\
\text { between sub- } \\
\text { groups }\end{array}$ & & & 0.02 & & $* * * 0.46$ & & $* 0.23$ & & 0.19 & & 0.11 \\
\hline \multirow[t]{4}{*}{ Change } & Mean & -0.88 & -0.99 & -0.76 & $\begin{array}{c}-0.96 \\
\end{array}$ & -0.70 & -1.14 & -0.69 & $\begin{array}{l}-0.91 \\
\end{array}$ & -0.86 & -1.10 & -0.70 \\
\hline & $\begin{array}{l}\text { Standard } \\
\text { deviation }\end{array}$ & 2.13 & 2.21 & 2.04 & 2.25 & 1.84 & 2.28 & 1.99 & 2.06 & 2.20 & 1.92 & 2.27 \\
\hline & $\begin{array}{r}\text { Effect size } \\
\text { between sub- } \\
\text { groups }\end{array}$ & & & 0.11 & & 0.12 & & 0.21 & & 0.02 & & $* 0.19$ \\
\hline & $\begin{array}{r}\text { Effect size } \\
\text { pre-COVID } \\
\text { vs COVID }\end{array}$ & $* * * 0.47$ & $* * * 0.52$ & $* * 0.41$ & $* * * 0.50$ & $* * 0.43$ & $* * * 0.60$ & $* * * 0.38$ & $* * 0.44$ & $* * * 0.50$ & $* * * 0.58$ & $* * 0.38$ \\
\hline
\end{tabular}

(b) Overall, how satisfied are you with your life nowadays? (0-10) 


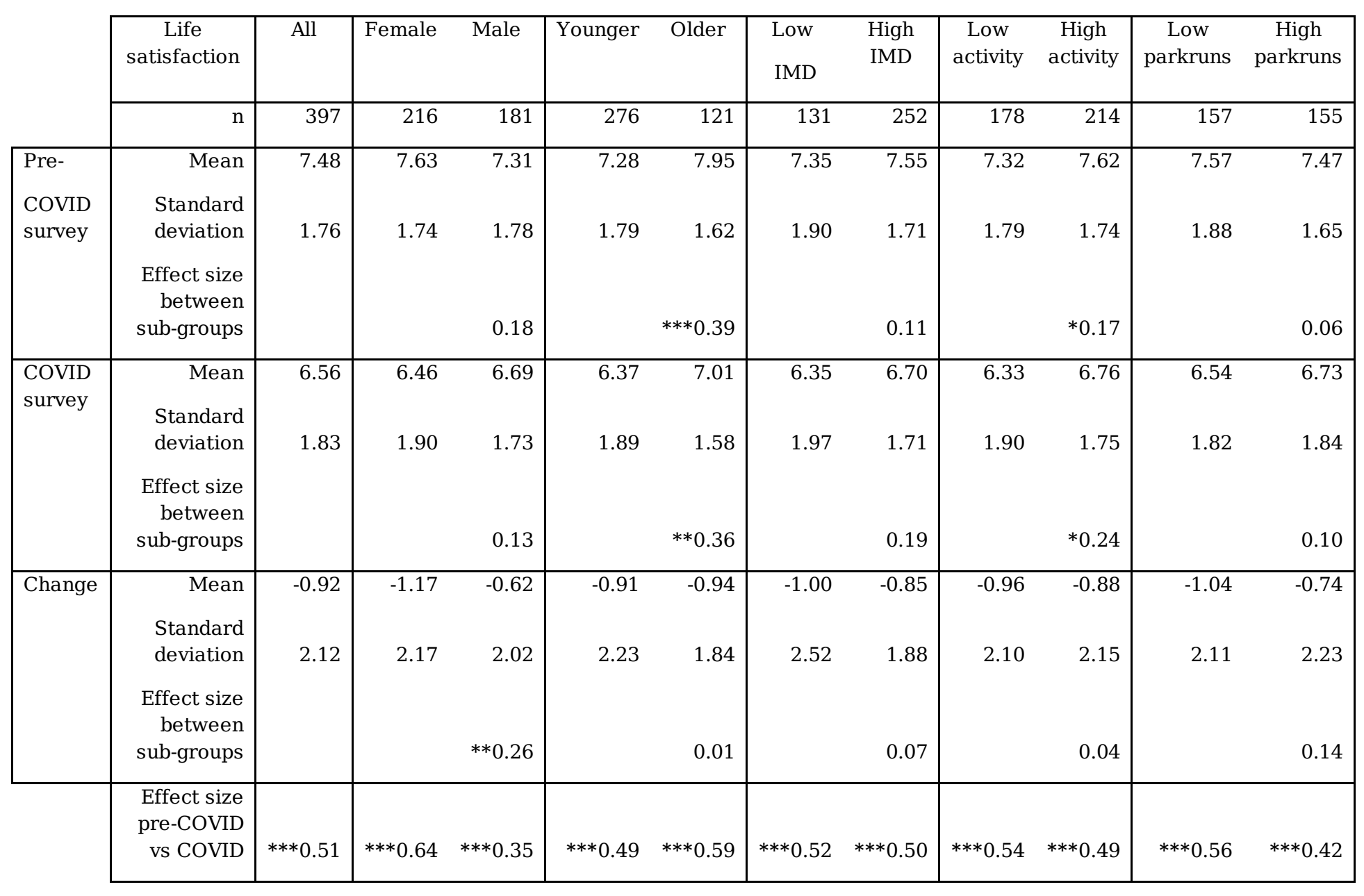

(c) In the past week, on how many days have you done a total of 30 minutes or more of physical activity, which was enough to raise your breathing rate? (0-7 days).

\begin{tabular}{|c|c|c|c|c|c|c|c|c|c|c|c|c|}
\hline & Physical activity & All & \multicolumn{2}{|c|}{ Female Male } & \multicolumn{2}{|c|}{ Younger Older } & \multicolumn{2}{|c|}{$\begin{array}{ll}\text { Low } & \text { High } \\
& \text { IMD }\end{array}$} & \multicolumn{2}{|c|}{$\begin{array}{cc}\text { Low } & \text { High } \\
\text { activity } & \text { activity }\end{array}$} & $\begin{array}{c}\text { Low } \\
\text { parkruns }\end{array}$ & $\begin{array}{c}\text { High } \\
\text { parkruns }\end{array}$ \\
\hline & $\mathrm{n}$ & 425 & 232 & 193 & 297 & 128 & 141 & 270 & 191 & 229 & 171 & 158 \\
\hline \multirow{3}{*}{$\begin{array}{l}\text { Pre- } \\
\text { COVID } \\
\text { survey }\end{array}$} & Mean & 3.47 & 3.36 & 3.61 & 3.49 & 3.42 & 3.49 & 3.43 & 2.60 & 4.22 & 3.43 & 3.48 \\
\hline & Stdev & 1.60 & 1.58 & 1.61 & 1.56 & 1.68 & 1.62 & 1.59 & 1.38 & 1.35 & 1.58 & 1.52 \\
\hline & $\begin{array}{r}\text { Effect size between } \\
\text { sub-groups }\end{array}$ & & & 0.16 & & 0.04 & & 0.04 & & $* * * 1.19$ & & 0.03 \\
\hline \multirow{3}{*}{$\begin{array}{l}\text { COVID } \\
\text { survey }\end{array}$} & Mean & 3.22 & 3.17 & 3.28 & 3.18 & 3.33 & 2.97 & 3.29 & 2.71 & 3.65 & 3.08 & 3.42 \\
\hline & Stdev & 1.97 & 1.93 & 2.01 & 1.94 & 2.04 & 1.87 & 2.00 & 1.87 & 1.91 & 1.87 & 2.02 \\
\hline & $\begin{array}{r}\text { Effect size between } \\
\text { sub-groups }\end{array}$ & & & 0.06 & & 0.08 & & 0.16 & & $* * * 0.50$ & & 0.17 \\
\hline \multirow[t]{4}{*}{ Change } & Mean & -0.21 & -0.19 & -0.33 & -0.32 & -0.09 & -0.52 & -0.14 & 0.10 & -0.57 & -0.36 & -0.06 \\
\hline & Standard deviation & 1.93 & 1.94 & 2.10 & 2.08 & 1.86 & 2.10 & 1.93 & 1.99 & 1.95 & 1.76 & 2.08 \\
\hline & $\begin{array}{r}\text { Effect size between } \\
\text { sub-groups }\end{array}$ & & & 0.07 & & 0.11 & & $* 0.19$ & & $* * 0.34$ & & 0.16 \\
\hline & $\begin{array}{l}\text { Effect size pre- } \\
\text { COVID vs COVID }\end{array}$ & $* 0.14$ & 0.11 & 0.18 & 0.18 & 0.05 & $* 0.30$ & 0.08 & 0.07 & $* * * 0.34$ & 0.20 & 0.03 \\
\hline
\end{tabular}


Mann-Whitney U test: ${ }^{*} \mathrm{p}<0.05 ; * * \mathrm{p}<0.01 ; * * \mathrm{p}<0.001$.

Effect size: Small 0-0.2; 0.2-0.5 moderate; large 0.5-0.8; very large 0.8-1.2; huge>2.0.

Table 3. Perceived change in happiness, life satisfaction, connections with others, mental health and physical activty due to the COVID-19 pandemic. Younger/older $<55$ and $\geq 55$ years; Low/high IMD $<50 \%$ and $\geq 50 \%$;

Low/high activity $\leq$ 'About 2 days per week' and $\geq$ 'About three days per week'; low/high parkruns $\leq 9$ runs and $>9$ runs.

(a) How has your happiness been impacted by the COVID-19 pandemic?

\begin{tabular}{|c|c|c|c|c|c|c|c|c|c|c|c|c|}
\hline Happiness & All & Female & Male & Younger & $\begin{array}{l}* * \\
\text { Older }\end{array}$ & $\begin{array}{l}\text { Low } \\
\text { IMD }\end{array}$ & $\begin{array}{l}\text { High } \\
\text { IMD }\end{array}$ & $\begin{array}{c}\text { Low } \\
\text { activity }\end{array}$ & $\begin{array}{c}\text { High } \\
\text { activity }\end{array}$ & $\begin{array}{c}\text { Low } \\
\text { parkruns }\end{array}$ & \multicolumn{2}{|c|}{$\begin{array}{c}\text { High } \\
\text { parkruns }\end{array}$} \\
\hline major negative impact & 31 & 17 & 14 & 30 & 1 & 18 & 12 & 12 & 18 & 11 & & 13 \\
\hline $\begin{array}{l}\text { moderate negative } \\
\text { impact }\end{array}$ & 278 & 157 & 121 & 184 & 85 & 87 & 181 & 129 & 145 & 122 & & 95 \\
\hline no impact & 96 & 48 & 48 & 62 & 33 & 26 & 68 & 45 & 51 & 31 & & 40 \\
\hline $\begin{array}{l}\text { moderate positive } \\
\text { impact }\end{array}$ & 40 & 25 & 15 & 28 & 10 & 17 & 23 & 16 & 24 & 15 & & 20 \\
\hline major positive impact & 5 & 2 & 3 & 2 & 3 & 1 & 3 & 1 & 4 & 1 & & 3 \\
\hline Total & 450 & 249 & 201 & 306 & 132 & 149 & 287 & 203 & 242 & 180 & & 171 \\
\hline major negative impact & $7 \%$ & $7 \%$ & $7 \%$ & $10 \%$ & ${ }^{\dagger \dagger}$ & $12 \%$ & $4 \%$ & $6 \%$ & $7 \%$ & $6 \%$ & & $8 \%$ \\
\hline impact & $62 \%$ & $63 \%$ & $60 \%$ & $60 \%$ & $64 \%$ & $58 \%$ & $63 \%$ & $64 \%$ & $60 \%$ & $68 \%$ & †† & $56 \%$ \\
\hline no impact & $21 \%$ & $19 \%$ & $24 \%$ & $20 \%$ & $25 \%$ & $17 \%$ & $24 \%$ & $22 \%$ & $21 \%$ & $17 \%$ & & $23 \%$ \\
\hline $\begin{array}{l}\text { moderate positive } \\
\text { impact }\end{array}$ & $9 \%$ & $10 \%$ & $7 \%$ & $9 \%$ & $8 \%$ & $11 \%$ & $8 \%$ & $8 \%$ & $10 \%$ & $8 \%$ & & $12 \%$ \\
\hline major positive impact & $1 \%$ & $1 \%$ & $1 \%$ & $1 \%$ & $2 \%$ & $1 \%$ & $1 \%$ & $0 \%$ & $2 \%$ & $1 \%$ & & $2 \%$ \\
\hline $\begin{array}{l}\text { moderate or major } \\
\text { negative }\end{array}$ & $69 \%$ & $70 \%$ & $67 \%$ & $70 \%$ & $65 \%$ & $70 \%$ & $67 \%$ & $69 \%$ & $67 \%$ & $74 \%$ & $\dagger$ & $63 \%$ \\
\hline no impact & $21 \%$ & $19 \%$ & $24 \%$ & $20 \%$ & $25 \%$ & $17 \%$ & $24 \%$ & $22 \%$ & $21 \%$ & $17 \%$ & & $23 \%$ \\
\hline $\begin{array}{l}\text { moderate or major } \\
\text { positive }\end{array}$ & $10 \%$ & $11 \%$ & $9 \%$ & $10 \%$ & $10 \%$ & $12 \%$ & $9 \%$ & $8 \%$ & $12 \%$ & $9 \%$ & & $13 \%$ \\
\hline
\end{tabular}

(b) How has your overall satisfaction with your life been impacted by the COVID-19 pandemic? 


\begin{tabular}{|c|c|c|c|c|c|c|c|c|c|c|c|}
\hline Life satisfaction & All & Female & Male & Younger & Older & $\begin{array}{l}\text { Low } \\
\text { IMD }\end{array}$ & $\begin{array}{l}\text { High } \\
\text { IMD }\end{array}$ & $\begin{array}{c}\text { Low } \\
\text { activity }\end{array}$ & $\begin{array}{c}\text { High } \\
\text { activity }\end{array}$ & $\begin{array}{c}\text { Low } \\
\text { parkruns }\end{array}$ & $\begin{array}{l}* \text { High } \\
\text { parkruns }\end{array}$ \\
\hline major negative impact & 27 & 19 & 8 & 23 & 3 & 10 & 15 & 8 & 18 & 12 & 11 \\
\hline $\begin{array}{l}\text { moderate negative } \\
\text { impact }\end{array}$ & 276 & 148 & 128 & 186 & 82 & 98 & 171 & 137 & 136 & 110 & 100 \\
\hline no impact & 88 & 46 & 42 & 56 & 30 & 21 & 63 & 32 & 55 & 37 & 33 \\
\hline $\begin{array}{l}\text { moderate positive } \\
\text { impact }\end{array}$ & 50 & 31 & 19 & 37 & 12 & 19 & 31 & 22 & 28 & 20 & 21 \\
\hline major positive impact & 8 & 5 & 3 & 4 & 4 & 1 & 6 & 3 & 5 & 1 & 5 \\
\hline Total & 449 & 249 & 200 & 306 & 131 & 149 & 286 & 202 & 242 & 180 & 170 \\
\hline major negative impact & $6 \%$ & $8 \%$ & $4 \%$ & $8 \%$ & $t^{+} \%$ & $7 \%$ & $5 \%$ & $4 \%$ & $7 \%$ & $7 \%$ & $6 \%$ \\
\hline $\begin{array}{l}\text { moderate negative } \\
\text { impact }\end{array}$ & $61 \%$ & $59 \%$ & $64 \%$ & $61 \%$ & $63 \%$ & $66 \%$ & $60 \%$ & $68 \%$ & $56 \%$ & $61 \%$ & $59 \%$ \\
\hline no impact & $20 \%$ & $18 \%$ & $21 \%$ & $18 \%$ & $23 \%$ & $14 \%$ & $\begin{array}{l}\dagger \\
22 \%\end{array}$ & $16 \%$ & $23 \%$ & $21 \%$ & $19 \%$ \\
\hline $\begin{array}{l}\text { moderate positive } \\
\text { impact }\end{array}$ & $11 \%$ & $12 \%$ & $10 \%$ & $12 \%$ & $9 \%$ & $13 \%$ & $11 \%$ & $11 \%$ & $12 \%$ & $11 \%$ & $12 \%$ \\
\hline major positive impact & $2 \%$ & $2 \%$ & $2 \%$ & $1 \%$ & $3 \%$ & $1 \%$ & $2 \%$ & $1 \%$ & $2 \%$ & $1 \%$ & $3 \%$ \\
\hline $\begin{array}{l}\text { moderate or major } \\
\text { negative }\end{array}$ & $67 \%$ & $67 \%$ & $68 \%$ & $68 \%$ & $65 \%$ & $72 \%$ & $65 \%$ & $72 \%$ & $64 \%$ & $68 \%$ & $65 \%$ \\
\hline no impact & $20 \%$ & $18 \%$ & $21 \%$ & $18 \%$ & $23 \%$ & $14 \%$ & $22 \%$ & $16 \%$ & $23 \%$ & $21 \%$ & $19 \%$ \\
\hline $\begin{array}{l}\text { moderate or major } \\
\text { positive }\end{array}$ & $13 \%$ & $14 \%$ & $11 \%$ & $13 \%$ & $12 \%$ & $13 \%$ & $13 \%$ & $12 \%$ & $14 \%$ & $12 \%$ & $15 \%$ \\
\hline
\end{tabular}

(c) How have your connections with others in your community been impacted by the COVID-19 pandemic? 


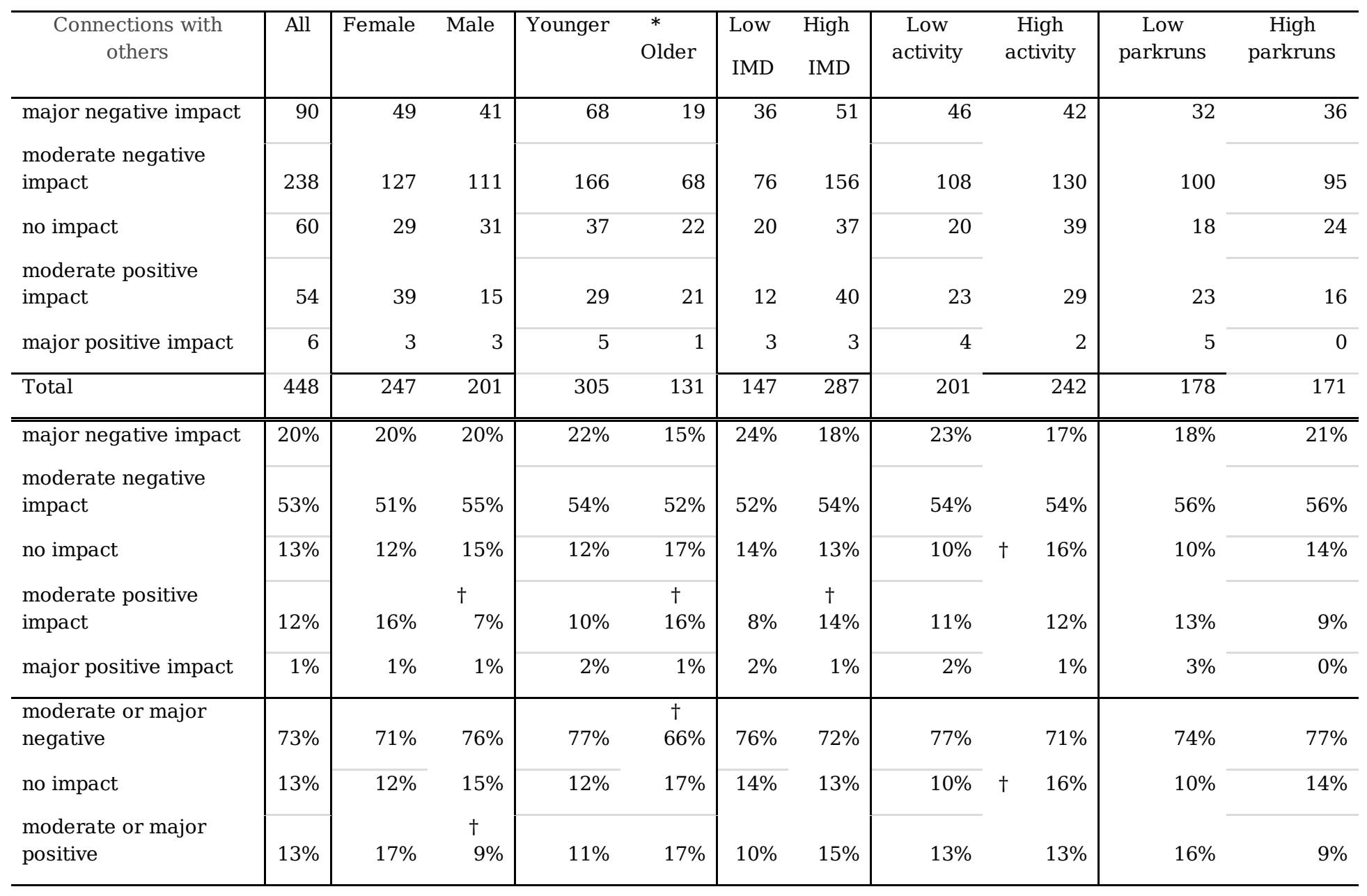

(d) How has your physical health been impacted by the COVID-19 pandemic? 


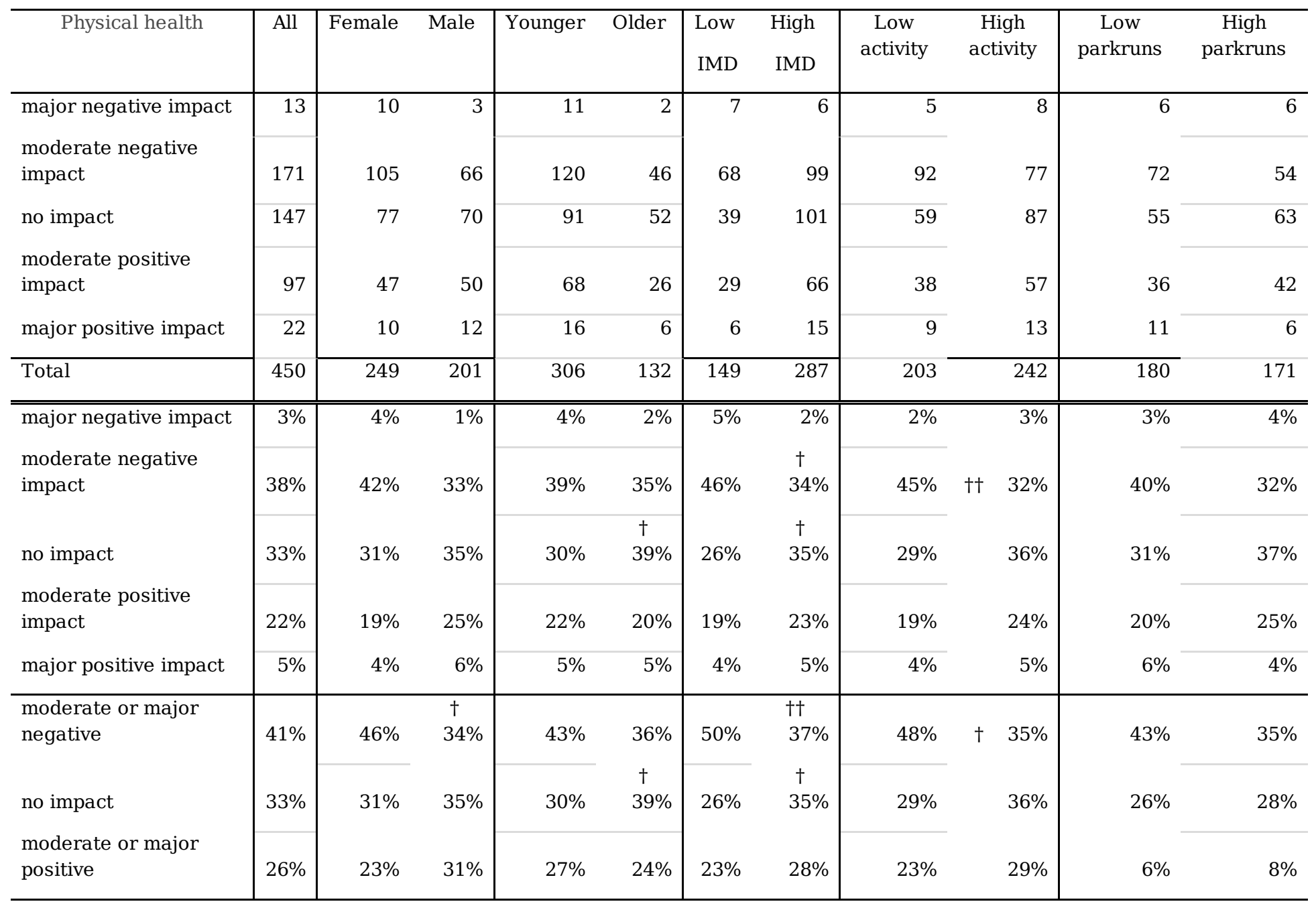

(e) How has your mental health been impacted by the COVID-19 pandemic? 


\begin{tabular}{|c|c|c|c|c|c|c|c|c|c|c|c|}
\hline Mental health & All & Female & Male & Younger & $\begin{array}{l}* * * \\
\text { Older }\end{array}$ & $\begin{array}{l}\text { Low } \\
\text { IMD }\end{array}$ & $\begin{array}{l}\text { High } \\
\text { IMD }\end{array}$ & $\begin{array}{c}\text { Low } \\
\text { activity }\end{array}$ & $\begin{array}{c}\text { High } \\
\text { activity }\end{array}$ & $\begin{array}{c}\text { Low } \\
\text { parkruns }\end{array}$ & $\begin{array}{c}\text { High } \\
\text { parkruns }\end{array}$ \\
\hline major negative impact & 30 & 21 & 9 & 29 & 1 & 10 & 18 & 12 & 18 & 11 & 15 \\
\hline $\begin{array}{l}\text { moderate negative } \\
\text { impact }\end{array}$ & 235 & 133 & 102 & 172 & 54 & 89 & 141 & 114 & 117 & 98 & 81 \\
\hline no impact & 155 & 80 & 75 & 85 & 68 & 41 & 107 & 66 & 88 & 61 & 59 \\
\hline $\begin{array}{l}\text { moderate positive } \\
\text { impact }\end{array}$ & 22 & 12 & 10 & 15 & 6 & 7 & 15 & 8 & 14 & 10 & 8 \\
\hline major positive impact & 6 & 3 & 3 & 4 & 2 & 2 & 4 & 3 & 3 & 0 & 6 \\
\hline Total & 448 & 249 & 199 & 305 & 131 & 149 & 285 & 203 & 240 & 180 & 169 \\
\hline major negative impact & $7 \%$ & $8 \%$ & $5 \%$ & $10 \%$ & $\begin{array}{l}+\dagger \\
1 \%\end{array}$ & $7 \%$ & $6 \%$ & $6 \%$ & $8 \%$ & $6 \%$ & $9 \%$ \\
\hline $\begin{array}{l}\text { moderate negative } \\
\text { impact }\end{array}$ & $52 \%$ & $53 \%$ & $51 \%$ & $56 \%$ & $\begin{array}{c}+\dagger \\
41 \%\end{array}$ & $60 \%$ & $\begin{array}{c}\dagger \\
49 \%\end{array}$ & $56 \%$ & $49 \%$ & $54 \%$ & $48 \%$ \\
\hline no impact & $35 \%$ & $32 \%$ & $38 \%$ & $28 \%$ & $\begin{array}{r}\text { ††† } \\
52 \%\end{array}$ & $28 \%$ & $\begin{array}{c}\dagger \\
38 \%\end{array}$ & $33 \%$ & $37 \%$ & $34 \%$ & $35 \%$ \\
\hline $\begin{array}{l}\text { moderate positive } \\
\text { impact }\end{array}$ & $5 \%$ & $5 \%$ & $5 \%$ & $5 \%$ & $5 \%$ & $5 \%$ & $5 \%$ & $4 \%$ & $6 \%$ & $6 \%$ & $5 \%$ \\
\hline major positive impact & $1 \%$ & $1 \%$ & $2 \%$ & $1 \%$ & $2 \%$ & $1 \%$ & $1 \%$ & $1 \%$ & $1 \%$ & $0 \%$ & $4 \%$ \\
\hline $\begin{array}{l}\text { moderate or major } \\
\text { negative }\end{array}$ & $59 \%$ & $62 \%$ & $56 \%$ & $66 \%$ & $\begin{array}{l}\text { ††† } \\
42 \%\end{array}$ & $66 \%$ & $\begin{array}{c}\dagger \\
56 \%\end{array}$ & $62 \%$ & $56 \%$ & $61 \%$ & $57 \%$ \\
\hline no impact & $35 \%$ & $32 \%$ & $38 \%$ & $28 \%$ & $\begin{array}{l}\text { TTТ } \\
52 \%\end{array}$ & $28 \%$ & $38 \%$ & $33 \%$ & $37 \%$ & $34 \%$ & $35 \%$ \\
\hline $\begin{array}{l}\text { moderate or major } \\
\text { positive }\end{array}$ & $6 \%$ & $6 \%$ & $7 \%$ & $6 \%$ & $6 \%$ & $6 \%$ & $7 \%$ & $5 \%$ & $7 \%$ & $6 \%$ & $8 \%$ \\
\hline
\end{tabular}

Chi-square test of differences between distributions of sub-groups: ${ }^{*} \mathrm{p}<0.05 ;{ }^{* *} \mathrm{p}<0.01 ;{ }^{* * *} \mathrm{p}<0.001$

Partitioned Chi-square test of differences between categories of sub-groups: $\uparrow \mathrm{p}<0.05 ; \uparrow+\uparrow p<0.0$

Table 4 Top two themes generated from open text responses with illustrative quotes 


\begin{tabular}{|l|l|l|}
\hline & Open text response theme and example quote & $\begin{array}{l}\text { Proportion } \\
\text { reporting } \\
\text { theme }\end{array}$ \\
\hline 1 & $\begin{array}{l}\text { Missing the parkrun community and socialisation } \\
\text { "There is something about being in a group of people that provides motivation, seeing } \\
\text { everyone else get up in the morning to go for a run or a walk, no matter their ages or fitness } \\
\text { levels. I could have easily ran the parkrun route in my local area without an organised event, } \\
\text { but I didn't, and I believe it is because the sense of community and connectedness inspires } \\
\text { me more than doing exercise because I 'have to' or 'should '." }\end{array}$ & $\begin{array}{l}22 \% \\
\text { Feeling little incentive/motive to continue being active in the absence of parkrun } \\
\text { "parkrun gives everyone who attends an incredible sense of belonging. Without parkrun I } \\
\text { have ran a significant amount less times a week (sometimes none at all) as I would normally } \\
\text { health has deteriorated because of the lack of exercise and community that parkrun brings } \\
\text { to my life. I am really looking forward to the reintroduction of the events sooner rather than } \\
\text { later." }\end{array}$ \\
\hline
\end{tabular}

\section{Supplementary Files}

This is a list of supplementary files associated with this preprint. Click to download.

- Supplementarymaterial2.docx

- Supplementarymaterial1.docx 